\title{
The Significance of Negative Lymph Nodes in Esophageal Cancer After Curative Resection: A Retrospective Cohort Study
}

This article was published in the following Dove Press journal: Cancer Management and Research

\author{
Junxian Mo ${ }^{1,2, *}$ \\ Dongni Chen ${ }^{3, *}$ \\ Changbo $\mathrm{Li}^{2}$ \\ Mingwu Chen' \\ 'Department of Cardio-Thoracic \\ Surgery, The First Affiliated Hospital of \\ Guangxi Medical University, Nanning, \\ Guangxi 53002I, People's Republic of \\ China; ${ }^{2}$ Department of Cardio-Thoracic \\ Surgery, The Seventh Affiliated Hospital \\ of Guangxi Medical University, Wuzhou, \\ Guangxi 543000, People's Republic of \\ China; ${ }^{3}$ Department of Thoracic \\ Oncology, State Key Laboratory of \\ Oncology in South China, Collaborative \\ Innovation Center for Cancer Medicine, \\ Sun Yat-sen University Cancer Center, \\ Guangzhou 510060, People's Republic of \\ China
}

*These authors contributed equally to this work
Correspondence: Mingwu Chen Department of Cardio-Thoracic Surgery, The First Affiliated Hospital of Guangxi Medical University, Nanning, Guangxi 53002I, People's Republic of China Email chenmingwu535@163.com
Objective: The impact of negative lymph nodes (NLNs) count on prognosis in esophageal cancer (EC) was analyzed using two institutions surgical database.

Methods: We conducted a retrospective study of $768 \mathrm{EC}$ patients treated by surgical resection between January 2010 and December 2012. The effects of the NLNs count on prognosis was analyzed. Cox regression model was conducted to determine the significant prognostic elements.

Results: The number of NLNs was studied as a categorical variable based on the quartiles (Q1: $\leq 15, \mathrm{Q} 2: 16-21, \mathrm{Q} 3: 22-30, \mathrm{Q} 4: \geq 31)$. And a better overall survival (OS) was observed with increasing number of NLNs $(\mathrm{HR}=0.762 ; 95 \% \mathrm{CI}, 0.596-0.974$ for $\mathrm{Q} 2, \mathrm{HR}=0.666$; 95\% CI, 0.516-0.860 for Q3 and $\mathrm{HR}=0.588$; 95\% CI, 0.450-0.768 for Q4) (all $P<0.05$ ). Multivariate regression analysis revealed that the NLNs count was an independent prognostic factor. Besides, for patients in T2 or T3 stage, a high number of NLNs was found to be significantly associated with a favorable OS (log rank $P<0.001)$.

Conclusion: A higher number of NLNs is independently related to the better OS in EC patients after surgical resection.

Keywords: esophageal cancer, negative lymph node, prognostic factor

\section{Introduction}

Esophageal cancer (EC) ranks as the sixth most common malignant carcinoma in China. ${ }^{1} \mathrm{EC}$ is approximately 3 to 4 times more prevalent in men than in women. The two main pathological types of EC are squamous cell carcinoma (SCC) and adenocarcinoma. SCC makes up approximately $90 \%$ of EC cases. ${ }^{2}$ Esophageal carcinoma has been proven to be one of the most aggressive cancers and often leads to a poor prognosis. Although considerable progress in surgical and oncological treatment has been made, five-year survival still remains low. Therefore, it is essential to identify reasonable prognostic indicators to make better treatment recommendations and improve prognosis. Prognostic factors for most gastrointestinal cancers that have been generally agreed upon include tumor size, lymph node (LN) involvement, distant metastasis and tumor differentiation. ${ }^{3}$

Esophageal carcinoma typically metastasizes via the lymphatic system; hence, lymph node status has been regarded as a strong prognostic factor. ${ }^{4}$ The International Union Against Cancer (UICC) and the American Joint Committee on Cancer (AJCC) have proposed the classification of the eighth edition for $\mathrm{N}$ stages according to the positive lymph nodes (PLNs) counts, ${ }^{5}$ which provides 
a more accurate evaluation of patient's outcome than the seventh edition. ${ }^{6}$ Lymph node status is considered as one of the most important prognostic factors in esophageal squamous cell carcinoma (ESCC) patients. However, inaccurate LN dissection and pathological evaluation may result in inappropriate pathologic nodal staging and treatment, a phenomenon called stage migration. ${ }^{7}$ Several new nodal staging classifications have been proposed to decide a more accurate nodal staging system, including the number of resected lymph nodes (RLNs), lymph node ratio (LNR), and the number of negative lymph nodes (NLNs). ${ }^{8-12}$ For example, for patients who underwent tri-incision esophagectomy, LNR has been regarded as an independent prognostic factor. ${ }^{8}$ According to the Surveillance, Epidemiology, and End Results (SEER) data, Smith reported that the number of LNs examined was an independent predictor for survival. ${ }^{13}$ However, the clinical value of treatment and prognosis of the NLNs count remains unclear. ${ }^{9,10,14}$ The aim of our study was to illustrate the relationship between the number of NLNs and the prognosis in EC patient. In addition, the association between the other clinicopathological factors and survival was evaluated.

\section{Patients and Methods Study Population}

1123 consecutive patients with ESCC underwent a curative operation at the first affiliated hospital of Guangxi Medical University (208 patients) and Sun Yat-sen University Cancer Center ( 925 patients) were the studied cohort from January, 2010 and December, 2012. Patients in our study have been pathologically confirmed ESCC and received primary surgical excision. All human data were collected according to a protocol approved by the ethics committee of the two institutions and under patient informed written consent. Patients with the esophageal tumor located in cervical or esophagogastric junction were excluded. In addition, patients died during perioperation or with the number of removed lymph nodes (RLNs) less than 12 were not included. They were also excluded if the histological subtype of malignancy was not ESCC. Patients with lacking data or missing were also ruled out. The final cohort had 768 patients, among which 138 and 630 patients were recruited in the first affiliated hospital of Guangxi Medical University and Sun Yat-sen University Cancer Center, respectively.

\section{Preoperative Evaluation}

The preoperative examination was comprised of computed tomography (CT), upper gastrointestinal (GI) barium swallow, GI endoscopy and tumor biopsy. Endoscopic ultrasound was later systematically added as part of the clinical staging. Patients were treated with esophagectomy provided preoperative evaluation manifested no proof of direct intrusion of the major vascular or trachea and distant metastases. The cardiopulmonary function was also evaluated routinely to assess medical operability.

\section{Surgical Resection}

Surgical techniques have been reported previously in details. $^{8,15}$ Briefly, three standard surgical methods were included: the Sweet approach (398 patients), the IvorLewis esophagectomy (46 patients), and the McKeown procedure (324 patients). In the Sweet approach, a left posterolateral incision was performed to remove the esophageal tumor. Once the esophagus was dissociated, and the diaphragm was incised to expose the abdominal cavity. The stomach was lifted to the chest and anastomosed the esophagus above or under the aortic arch. In the IvorLewis method, the stomach was dissected through the midline laparotomy. Then, an esophagectomy was performed with a right thoracotomy. The stomach was brought to the right cupula of pleura through the esophageal hiatus with an esophagogastric anastomosis. In the McKeown approach, a right posterolateral thoracotomy was performed initially, allowing for resection of the esophageal tumor and mediastinal lymphadenectomy. Afterwards, an abdominal incision was made to mobilize the stomach. A left cervical incision was performed for the anastomosis. Lymphadenectomy in the mediastinum and abdomen was conventionally performed, while the cervical LN resection was not routinely carried out.

\section{Pathological Examination}

All resected specimens were examined by pathology. The number of LN was counted with low-power field microscopy. The number of metastatic and examined LNs in each station was recorded. The pathologic tumor and LN staging were based on the eighth edition of the AJCC/ UICC TNM classification system. ${ }^{5,16}$ The TLNs were calculated as the total number of LNs resected in the cervical, thoracic, and abdominal regions. 


\section{Follow-Up of Participants}

For the first year, patients were followed up every three months, and then for the following three years, patients were suggested for follow-up every half year, then annually thereafter. The patients who included were followed up until January 2019. The mean follow-up time was 43.55 months (range 1-95 months).

\section{Statistics Analysis}

A $\chi^{2}$ test was used to compare categorical variables and the analysis of variance (ANOVA) was applied for the comparison of continuous variables. Kaplan-Meier method was used to plot the survival curves, and the log rank analysis was used to evaluate differences in prognosis between groups. Cox proportional hazards model was conducted to clarify the significant prognostic factors. The endpoint of our study was overall survival (OS). OS was defined as the number of days between the date of diagnosis and the date of anycause death or the date of the last follow-up. All calculations were analyzed using SPSS 20.0 (SPSS, Chicago, IL), and $p<$ 0.05 was considered significant. Our method reporting is consistent with the STROCSS guidelines. ${ }^{17}$

\section{Results}

\section{Patient Characteristics and Overall Survival}

768 patients were included in the analysis. The median TLN was 23 (range 12 to 89), and the mean TLN was 26.75 (SD 13.13). To assess the prognostic effect of the NLN count, patients were divided into different groups according to the NLN quartiles. There were four groups in the following distribution: 174 patients in group $1(\mathrm{NLN} \leq 15), 200$ patients in group 2 (NLN 16 to 21), 199 patients in group 3 (NLN 22 to 30 ), and 195 patients in group 4 (NLN $\geq 31$ ). The relationship between the patient's demographics and NLN count is presented in Table 1. Overall, there were no significant differences between patients in the four groups regarding the age, sex, pathological type, $\mathrm{T}$ (tumor) stage, metastatic LNs, differentiation, tumor location, TNM-stage, margin status, neoadjuvant or postoperative chemoradiation therapy (CRT), and recurrence or metastasis (all $P>0.05$ ). Nevertheless, NLN count was significantly associated with surgical approach, and surgical complications (all $P<0.001$ ) (Table 1). In the current study, median OS was 58.0 months (95\% confidence interval [CI] 55.0-61.0 months), and the overall 1-, 3-, and 5-year survival rates were $85.0 \%, 62.0 \%$, and $35.7 \%$, respectively.

\section{Negative LNs Count and Patient Prognosis}

There was a total of 427 overall deaths during the followup period. A Cox regression analysis was conducted to study the relationship between the number of NLNs and long-term prognosis. The NLN count was used as a categorical variable for analysis (i.e. Q1, Q2, Q3, and Q4). The univariate COX analysis revealed that the following factors significantly correlated with OS: age, sex, histology type, negative and positive LN count, tumor stage of T3, moderate and poor differentiation, stage IV tumor recurrence or metastasis, and postoperative adjuvant CRT (Table 2). After adjusting covariates that were significant in the univariate analysis, multivariate analysis suggested lower overall mortalities in Q2, Q3 and Q4 cases compared to Q1 cases (HR $=0.762$; 95\% CI, 0.596-0.974 for $\mathrm{Q} 2, \mathrm{HR}=0.666$; 95\% CI, $0.516-0.860$ for $\mathrm{Q} 3$ and $\mathrm{HR}=0.588 ; 95 \% \mathrm{CI}, 0.450-0.768$ for $\mathrm{Q} 4$ ) (all $P<0.05)$. Additionally, variables independently associated with poor survival were male, older age, LN involvement, recurrence, and tumor metastasis. On the contrary, adjuvant therapy after surgery was related to better OS (HR= 0.741; 95\% CI, 0.575-0.956; $P=0.021$ ) (Table 2).

As the Kaplan-Meier survival curves presented, patients in groups 3 and 4 had better OS than the patients in groups 1 and $2(\log$ rank $=17.898 ; P<0.001$; Figure 1A). Afterwards, patients were classified into either high NLN count (groups 3 and 4) or low NLN count (groups 1 and 2) in the following analyses. The high NLNs counts group showed a median survival time of 63.6 months (95\% CI: 60.0 to 67.0 ) and a 5 -year survival rate of $38.6 \%$. In addition, the low NLNs group had a median survival period of 52.6 months $(95 \% \mathrm{CI}$ : 49.2 to 56.0$)$ and a 5 -year survival rate of $29.2 \%(\log$ rank= 15.128; $P<0.001$; Figure 1B). The impact of NLNs on OS was analyzed after stratification by $\mathrm{T}$ stage. For patients with T2 or T3 stage, a higher NLN count was significantly associated with better prognosis $(\log \operatorname{rank}=18.851 ; P<0.001$; Figure 2A). However, the correlation was not observed for T0 or T1 patients (log rank $=0.002 ; P=0.996$; Figure 2B). Stratification depending on $\mathrm{N}$ (lymph node) stage presented similar results. More NLNs count was proved to be a significant protective prognostic factor in N0 patients (log rank $=7.243 ; P=0.007$; Figure $3 \mathrm{~A}$ ), and the protective effect was also found in $\mathrm{pN}+$ patients with concomitant $\mathrm{LN}$ metastasis (log rank $=7.686 ; P=0.006$; Figure $3 \mathrm{~B})$. In addition, we evaluated whether the surgical approach modified the effect of NLN count on OS, and a significant interaction between 
Table I Baseline Characteristics of Patients Stratified for the Number of Negative Lymph Nodes

\begin{tabular}{|c|c|c|c|c|c|c|}
\hline \multirow[t]{3}{*}{ Demographics } & \multirow[t]{3}{*}{ Total n (\%) } & \multicolumn{4}{|c|}{ Numbers of Negative Lymph Nodes (Quartiles) } & \multirow[t]{3}{*}{$P$ value } \\
\hline & & Group I & Group 2 & Group 3 & Group 4 & \\
\hline & & $\leq \mathbf{1 5}$ & $|6-2|$ & $22-30$ & $\geq 3 \mathbf{I}$ & \\
\hline Number & 768 & 174 & 200 & 199 & 195 & \\
\hline Age $(y)$ & $59.16 \pm 9.13$ & $59.78 \pm 10.00$ & $60.01 \pm 9.38$ & $57.86 \pm 8.66$ & $59.07 \pm 8.42$ & 0.087 \\
\hline \multicolumn{7}{|l|}{ Sex } \\
\hline Female & 163 & $37(21.3)$ & $42(21.0)$ & $46(23.1)$ & $38(19.5)$ & 0.853 \\
\hline Male & 605 & $137(78.7)$ & $158(79.0)$ & $153(76.9)$ & $157(80.5)$ & \\
\hline \multicolumn{7}{|l|}{ Histological Type } \\
\hline SCC & 738 & 163 (93.7) & $196(98.0)$ & $188(94.5)$ & $191(97.9)$ & 0.050 \\
\hline After CRT & 30 & $\mathrm{II}(6.3)$ & $4(2.0)$ & II (5.5) & $4(2.1)$ & \\
\hline \multicolumn{7}{|l|}{ Tumor } \\
\hline 0 & 30 & $11(6.3)$ & $4(2.0)$ & II (5.5) & $4(2.1)$ & \\
\hline 1 & 77 & $16(9.2)$ & $24(12.0)$ & $16(8.0)$ & $21(10.8)$ & 0.221 \\
\hline 2 & 153 & $4 I(23.6)$ & $38(19.0)$ & $36(18.1)$ & $38(19.5)$ & \\
\hline 3 & 508 & $106(60.9)$ & $134(67.0)$ & $136(68.3)$ & $132(67.7)$ & \\
\hline \multicolumn{7}{|l|}{ Node } \\
\hline 0 & 394 & $78(44.8)$ & $103(51.5)$ & III(55.8) & $102(52.3)$ & \\
\hline I & 209 & $53(30.5)$ & $54(27.0)$ & $50(25.1)$ & $52(26.7)$ & 0.657 \\
\hline 2 & 121 & $29(16.7)$ & $30(15.0)$ & $30(15.1)$ & $32(16.4)$ & \\
\hline 3 & 44 & $14(8.0)$ & $13(6.5)$ & $8(4.0)$ & $9(4.6)$ & \\
\hline \multicolumn{7}{|l|}{ Grade } \\
\hline G0 & 33 & $I I(6.3)$ & $3(1.5)$ & $12(6.0)$ & $7(3.6)$ & \\
\hline GI & 133 & $25(14.4)$ & $44(22.0)$ & $33(16.6)$ & $31(15.9)$ & 0.216 \\
\hline G2 & 379 & $87(50.0)$ & $100(50.0)$ & $92(46.2)$ & $100(51.3)$ & \\
\hline G3 & 223 & $51(29.3)$ & $53(26.5)$ & $62(31.2)$ & $57(29.2)$ & \\
\hline \multicolumn{7}{|l|}{ Location } \\
\hline Upper third & 87 & $17(9.8)$ & $17(8.5)$ & $27(13.6)$ & $26(13.3)$ & \\
\hline Middle third & 323 & $66(37.9)$ & $81(40.5)$ & $94(47.2)$ & $82(42.1)$ & 0.125 \\
\hline Lower third & 358 & $91(52.3)$ & $102(51.0)$ & $78(39.2)$ & $87(44.6)$ & \\
\hline \multicolumn{7}{|l|}{ Stage } \\
\hline 0 & 30 & $\mathrm{II}(6.3)$ & $4(2.0)$ & $\mathrm{II}(5.5)$ & $4(2.1)$ & \\
\hline I & 19 & $3(1.7)$ & $6(3.0)$ & $4(2.0)$ & $6(3.1)$ & \\
\hline II & 240 & $59(33.9)$ & $65(32.5)$ & $58(29.1)$ & $58(29.7)$ & 0.246 \\
\hline III & 435 & $87(50.0)$ & $112(56.0)$ & $118(59.3)$ & $118(60.5)$ & \\
\hline IV & 44 & $14(8.0)$ & $13(6.5)$ & $8(4.0)$ & $9(4.6)$ & \\
\hline \multicolumn{7}{|l|}{ Margin Status } \\
\hline Not Involved (R0) & 741 & $164(94.3)$ & $195(97.5)$ & 194(97.5) & $188(96.4)$ & 0.289 \\
\hline Involved (RI) & 27 & $10(5.7)$ & $5(2.5)$ & $5(2.5)$ & $7(3.6)$ & \\
\hline Tumor Length & $3.77 \pm 3.92$ & $4.03 \pm 7.71$ & $3.62 \pm 1.59$ & $3.66 \pm 1.67$ & $3.79 \pm 1.57$ & $0.76 \mathrm{I}$ \\
\hline \multicolumn{7}{|l|}{ Preoperative CRT } \\
\hline No & 687 & $103(59.2)$ & $178(89.0)$ & $173(86.9)$ & $182(93.3)$ & 0.488 \\
\hline Yes & 81 & $7 I(40.8)$ & $22(11.0)$ & $26(13.1)$ & $13(6.7)$ & \\
\hline \multicolumn{7}{|l|}{ Postoperative CRT } \\
\hline No & 490 & $142(61.5)$ & $127(63.5)$ & $|3|(65.8)$ & $129(66.2)$ & 0.719 \\
\hline Yes & 278 & $89(38.5)$ & $73(36.5)$ & $68(34.2)$ & $66(33.8)$ & \\
\hline
\end{tabular}

(Continued) 
Table I (Continued).

\begin{tabular}{|c|c|c|c|c|c|c|}
\hline \multirow[t]{3}{*}{ Demographics } & \multirow[t]{3}{*}{ Total n (\%) } & \multicolumn{4}{|c|}{ Numbers of Negative Lymph Nodes (Quartiles) } & \multirow[t]{3}{*}{$P$ value } \\
\hline & & Group I & Group 2 & Group 3 & Group 4 & \\
\hline & & $\leq \mathbf{1 5}$ & $|6-2|$ & $22-30$ & $\geq 3 \mathbf{l}$ & \\
\hline \multicolumn{7}{|l|}{ Recurrence or Metastasis } \\
\hline Neither & 578 & $130(74.7)$ & $146(73.0)$ & $151(75.9)$ & $151(77.4)$ & \\
\hline Recurrence & 34 & $12(6.9)$ & II (5.5) & $6(3.0)$ & $5(2.6)$ & 0.681 \\
\hline Metastasis & 128 & $25(14.4)$ & $36(18.0)$ & $35(17.6)$ & $32(16.4)$ & \\
\hline Both & & 28 & $7(4.0)$ & $7(3.5)$ & $7(3.5)$ & $7(3.6)$ \\
\hline \multicolumn{7}{|l|}{ Surgical Approach } \\
\hline Left thoracotomy & 398 & $133(76.4)$ & $136(68.0)$ & $92(46.2)$ & $37(19.0)$ & \\
\hline Ivor-Lewis & 46 & $6(3.4)$ & $15(7.5)$ & $12(6.0)$ & $13(6.7)$ & $<0.001$ \\
\hline 3-incision & & 324 & $35(20.1)$ & $49(24.5)$ & $95(47.7)$ & $145(74.4)$ \\
\hline \multicolumn{7}{|l|}{ Complication } \\
\hline No & 629 & I58(90.8) & $167(83.5)$ & $163(81.9)$ & $|4|(72.3)$ & $<0.001$ \\
\hline Yes & 139 & $16(9.2)$ & $33(16.5)$ & $36(18.1)$ & $(27.7)$ & \\
\hline
\end{tabular}

Note: Data are mean \pm SD or $\mathrm{n}(\%)$

Abbreviations: CRT, chemoradiation therapy; G0, after neoadjuvant CRT and no residual carcinoma; GI, well differentiated; G2, moderately differentiated; G3, poorly differentiated; SCC, squamous cell carcinoma.

NLNs and surgical approach was elucidated. In cases using the three-incision approach, a higher number of NLNs was significantly related to lower death rate $(\log$ rank= 20.374; $P<0.001$; Figure 4A), but a similar positive effect was not found in cases with left-thoracotomy or Ivor-Lewis approaches $(\log \operatorname{rank}=0.713 ; P=0.398, \log \operatorname{rank}=2.166$; $P=0.141$; Figure 4B and $\mathrm{C}$, respectively). Moreover, we conducted the survival analysis in patients with and without neoadjuvant CRT separately. It was found that in either group, a high number of NLNs contributed to a favorable prognosis $(\log$ rank $=10.804 ; P<0.001, \log$ rank=5.599; $P=0.018$; Figure $5 \mathrm{~A}$ and $\mathrm{B}$, respectively).

\section{Discussion}

The current study evaluated the outcomes of 768 Chinese ESCC patients to clarify the prognostic value of NLN counts. Our results suggested that the number of NLNs was an independent prognostic factor for ESCC patients undergoing radical esophagectomy. We discovered that ESCC patients with higher NLN counts showed better survival than those with lower NLN counts, which was consistent with the findings of previous studies. ${ }^{10,11,14}$

Resecting more LNs may contribute to a better evaluation of LN metastasis and a more accurate $\mathrm{pN}$ stage. However, the optimal LNs count to be resected remains uncertain. UICC proposed $6 \mathrm{LNs}$ for resection, but there was a lack of specific evidence from a large series study. The number of LNs removed during surgery differed widely because of the different extent of disease and method of lymphadenectomy adopted by different hospitals. Japanese surgeons resected the most LNs per operation with a mean number of 43 and 90 for two-field and three-field lymphadenectomy, respectively. ${ }^{18}$ Bollschweiler et al reported that resecting more than 15 LNs resulted in a better prognosis than examining fewer LNs for patients classified as pN0. ${ }^{19}$ Greenstein et al found that patients undergoing the operation for EC should have at least $18 \mathrm{LNs}$ resected. ${ }^{20}$ The number of removed LNs varied from 3 to 25 in most Chinese studies. Hu et al proposed that more than 6 LNs ought to be removed for an appropriate assessment of the pN stage in ESCC patients. ${ }^{18}$ RLNs include PLNs; therefore, using the number of RLNs as a prognosis factor may attenuate accuracy. In the present study, the number of NLNs was used to predict the patient's outcome. We found that the NLNs count had prognostic value on $\mathrm{pN} 0$ patients as well as pN1-3 patients, and the prognostic value was more accurate than that of RLN counts. Additionally, as reported, we noticed that it was various for the cutoff point of the NLN count. 9,10,14 This might be the consequence of differences in surgical approaches and the statistical analysis technique. In future researches, it will be essential to identify exact numbers of NLNs in patients with esophageal carcinoma and to determine optimal cutoff points.

It is ambiguous that the underlying mechanism of why the NLNs count can be applied to evaluate ESCC patient's 
Table 2 Cox Regression Analysis of Prognostic Factors Influencing Overall Survival

\begin{tabular}{|c|c|c|c|c|c|c|}
\hline \multirow[t]{2}{*}{ Variables } & \multicolumn{3}{|c|}{ Univariate Analysis } & \multicolumn{3}{|c|}{ Multivariate Analysis } \\
\hline & HR & $95 \% \mathrm{Cl}$ & $P$ value & HR & $95 \% \mathrm{Cl}$ & $P$ value \\
\hline Age & 1.021 & $1.010-1.032$ & $<0.001$ & 1.028 & $1.016-1.039$ & $<0.001$ \\
\hline \multicolumn{7}{|l|}{ Sex } \\
\hline Female & 1 & 1 & - & I & 1 & - \\
\hline Male & 1.369 & $1.064-1.763$ & 0.015 & 1.281 & $1.001-1.639$ & 0.049 \\
\hline \multicolumn{7}{|l|}{ Histological Type } \\
\hline After CRT & 1 & 1 & - & I & 1 & - \\
\hline SCC & 1.918 & $1.054-3.492$ & 0.033 & $2.34 I$ & $1.038-5.278$ & 0.040 \\
\hline \multicolumn{7}{|l|}{ Negative Lymph Nodes } \\
\hline QI & 1 & 1 & - & I & 1 & - \\
\hline Q2 & 0.875 & $0.680-1.124$ & 0.295 & 0.762 & $0.596-0.974$ & 0.030 \\
\hline Q3 & 0.620 & $0.474-0.817$ & $<0.001$ & 0.666 & $0.516-0.860$ & $<0.001$ \\
\hline Q4 & 0.624 & $0.476-0.817$ & 0.001 & 0.588 & $0.450-0.768$ & $<0.001$ \\
\hline \multicolumn{7}{|l|}{ Tumor } \\
\hline 0 & 1 & 1 & - & I & I & - \\
\hline I & 0.926 & $0.458-1.874$ & 0.831 & 0.803 & $0.396-1.630$ & 0.544 \\
\hline 2 & 1.495 & $0.794-2.817$ & 0.213 & 1.104 & $0.583-2.092$ & 0.762 \\
\hline 3 & 2.284 & $1.25 I-4.168$ & 0.007 & 1.679 & $0.914-3.086$ & 0.095 \\
\hline \multicolumn{7}{|l|}{ Node } \\
\hline 0 & 1 & I & - & I & 1 & - \\
\hline 1 & 0.495 & $0.392-0.625$ & $<0.001$ & 1.965 & $1.54 \mathrm{I}-2.506$ & $<0.001$ \\
\hline 2 & 1.500 & $1.151-1.956$ & 0.003 & 2.997 & $2.263-3.970$ & $<0.001$ \\
\hline 3 & 2.623 & I.847-3.726 & $<0.001$ & 5.312 & $3.626-7.78 \mid$ & $<0.001$ \\
\hline \multicolumn{7}{|l|}{ Grade } \\
\hline 0 & 1 & I & - & I & 1 & - \\
\hline 1 & 1.556 & $0.839-2.886$ & 0.160 & 1.592 & $0.520-4.878$ & 0.415 \\
\hline 2 & 1.977 & I. $105-3.537$ & 0.022 & 1.817 & $0.606-5.45$ I & 0.286 \\
\hline 3 & 2.209 & $1.223-3.987$ & 0.009 & 1.843 & $0.612-5.553$ & 0.277 \\
\hline \multicolumn{7}{|l|}{ TNM Stage } \\
\hline 0 & I & 1 & - & I & I & - \\
\hline 1 & 0.799 & $0.350-1.826$ & 0.595 & 0.788 & $0.151-4.111$ & 0.778 \\
\hline II & 1.370 & $0.805-2.330$ & 0.245 & 0.743 & $0.217-2.549$ & 0.637 \\
\hline III & 1.153 & $0.684-1.942$ & 0.593 & 0.629 & $0.199-1.993$ & 0.431 \\
\hline IV & 3.703 & $2.052-6.684$ & $<0.001$ & 3.143 & $0.953-10.373$ & 0.060 \\
\hline \multicolumn{7}{|l|}{ Margin Status } \\
\hline Not Involved (R0) & 1 & 1 & & - & & \\
\hline Involved (RI) & 1.362 & $0.849-2.184$ & 0.200 & & & \\
\hline Tumor Length & 1.008 & $0.992-1.024$ & 0.333 & & & \\
\hline \multicolumn{7}{|l|}{ Preoperative CRT } \\
\hline No & I & 1 & & & & \\
\hline Yes & 1.050 & $0.768-1.435$ & 0.759 & & & \\
\hline \multicolumn{7}{|l|}{ Postoperative CRT } \\
\hline No & I & I & - & I & 1 & - \\
\hline Yes & 0.388 & $0.143-0.684$ & 0.001 & 0.741 & $0.575-0.956$ & 0.021 \\
\hline
\end{tabular}

(Continued) 
Table 2 (Continued).

\begin{tabular}{|c|c|c|c|c|c|c|}
\hline \multirow[t]{2}{*}{ Variables } & \multicolumn{3}{|c|}{ Univariate Analysis } & \multicolumn{3}{|c|}{ Multivariate Analysis } \\
\hline & HR & $95 \% \mathrm{Cl}$ & $P$ value & HR & $95 \% \mathrm{Cl}$ & $P$ value \\
\hline \multicolumn{7}{|l|}{ Recurrence or Metastasis } \\
\hline Neither & I & I & - & 1 & I & - \\
\hline Recurrence & 2.006 & $1.340-3.001$ & 0.001 & 1.714 & $1.129-2.600$ & 0.011 \\
\hline Metastasis & 1.948 & $1.545-2.456$ & $<0.001$ & 1.861 & $1.425-2.430$ & $<0.001$ \\
\hline Both & 2.073 & $1.342+3.203$ & 0.001 & 1.872 & $1.203-2.913$ & 0.005 \\
\hline \multicolumn{7}{|l|}{ Surgical Approach } \\
\hline Left thoracotomy & I & I & - & & & \\
\hline Ivor-Lewis & 0.775 & $0.505-1.189$ & 0.242 & & & \\
\hline 3-incision & 0.818 & $0.668-1.001$ & 0.051 & & & \\
\hline \multicolumn{7}{|l|}{ Complication } \\
\hline No & I & 1 & - & & & \\
\hline Yes & 1.157 & $0.900-1.487$ & 0.256 & & & \\
\hline
\end{tabular}

prognosis. Generally, H\&E staining is applied for the routine pathological examination of LNs. Nevertheless, previous studies have reported that hematoxylin and eosin (H\&E) staining is inferior to immunohistochemistry (IHC) for detecting involved LNs. Thompson et al reported a study, which included 119 node-negative (pN0) patients. After serial sectioning and IHC of the LNs, 88 patients (74\%) had their primary status confirmed, while twenty-two $(18 \%)$ were found isolated tumor cells or clusters, $8(7 \%)$ were detected micrometastases, and $1(1 \%)$ had an LN metastasis. ${ }^{21}$ A study by Koenig and colleagues confirmed that isolated tumor cells detectable in LNs by IHC are reliable prognostic indicators in patients with EC regardless of the pathological N-status. Patients who were classified as pN0 with micro involvement in an LN had a poor prognosis which nearly equaled to the patients with histologically detected nodal involvement $(\mathrm{pN} 1) .^{22}$ Therefore, a higher number of NLNs may make it more likely to detect micro involvement. Resecting more NLNs was more likely to remove the micrometastatic tumor cell, which may be the reason why patients with more NLNs had a better prognosis in our study.
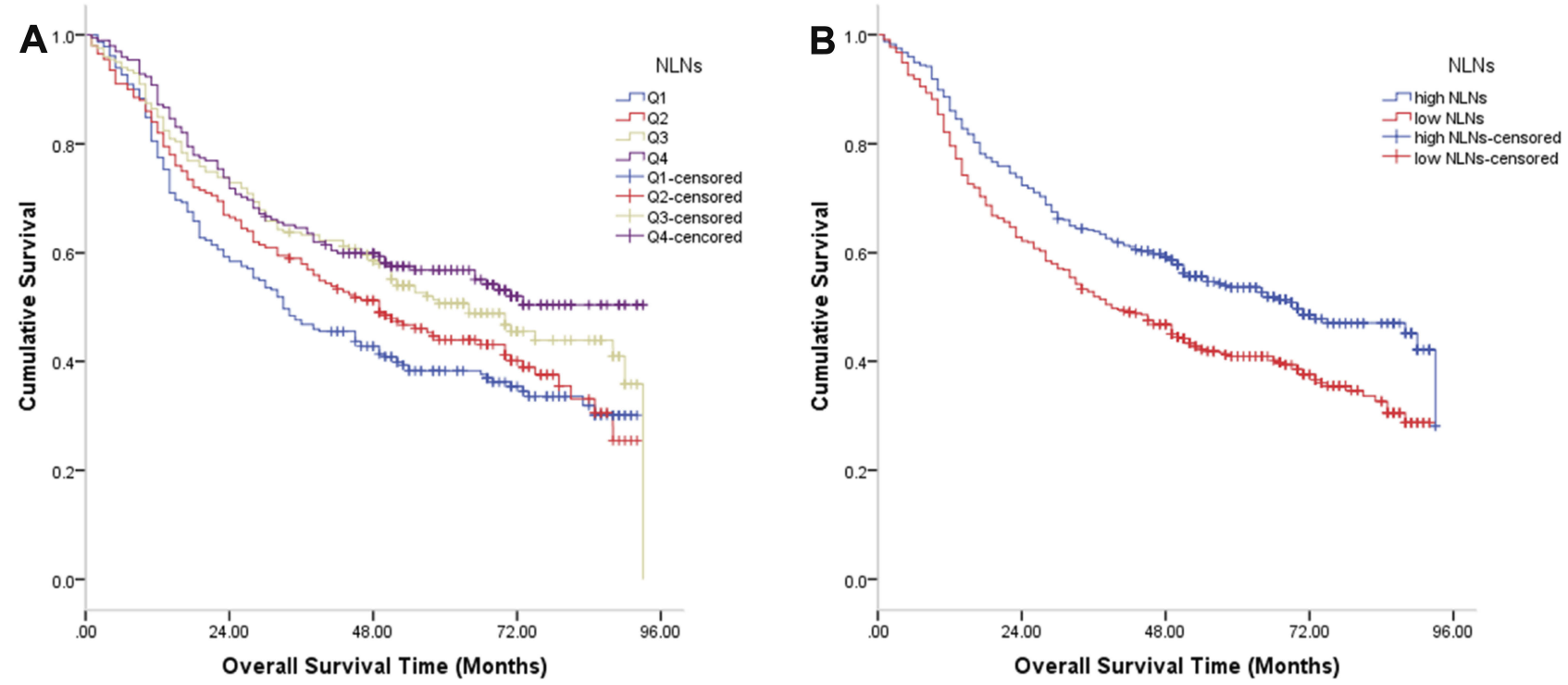

Figure I (A) There are significant survival differences between NLNs in Q1, Q2. Q3 and Q4. (B) Patients in high NLNs group had significantly better survival rates than patients in low NLNs group. 

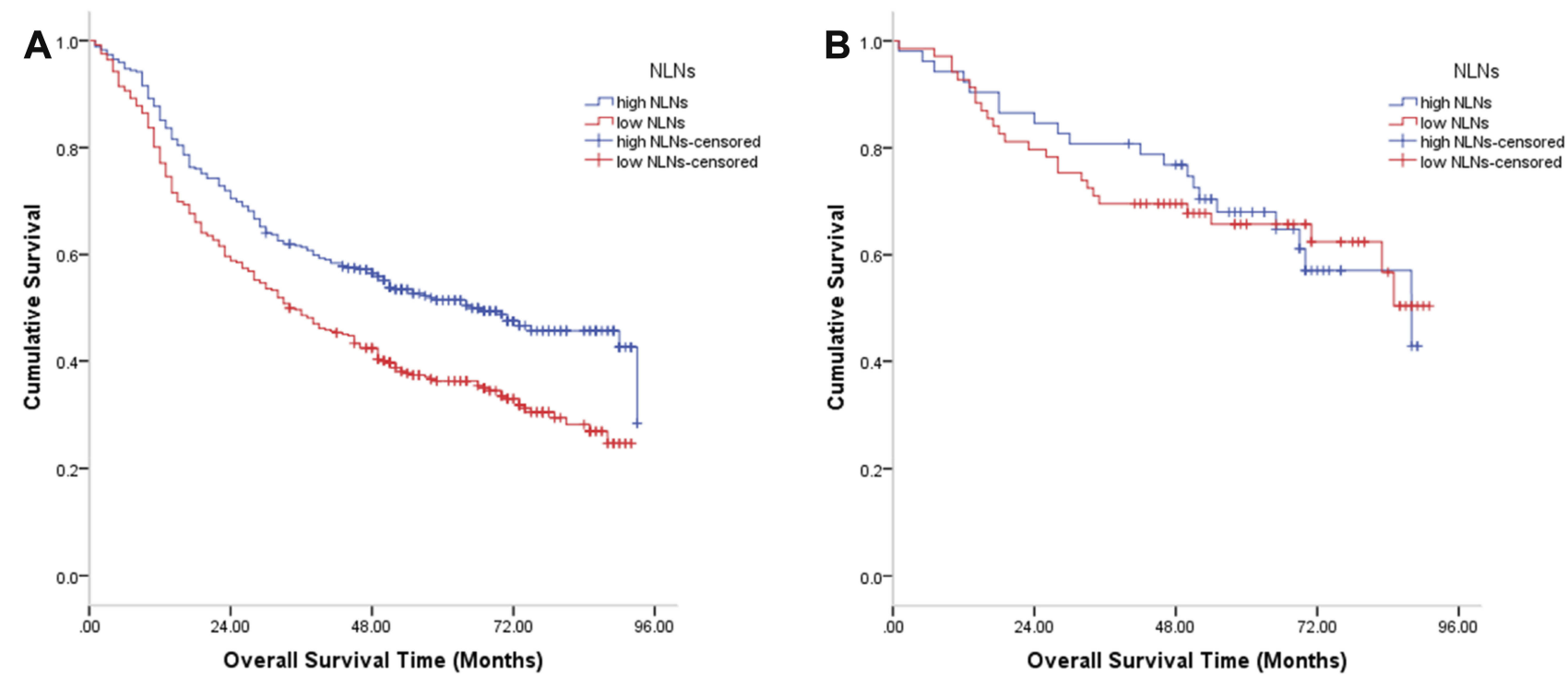

Figure 2 (A) A significant survival difference was noted between high NLNs group and low NLNs group in patients with T2/3 stage tumors. (B) No survival difference was found between high NLNs group and low NLNs group for patients with TO/I stage tumors.
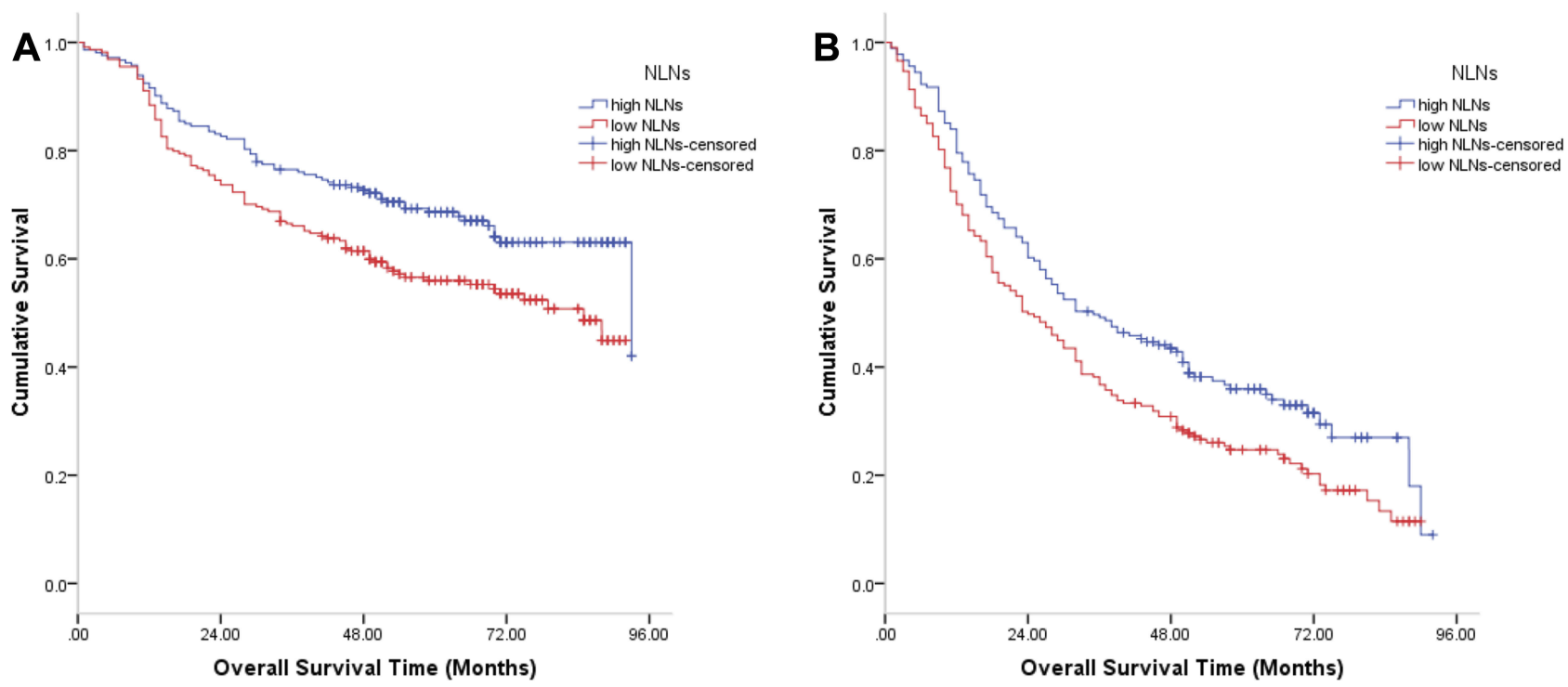

Figure 3 (A) A significant survival difference was noted between high NLNs group and low NLNs group for patients with N0 stage tumors. (B) A significant survival difference was observed between high NLNs group and low NLNs group for patients with node-positive esophageal cancers.

Another explanation for the relationship between the number of NLNs and the improved outcome is inadequate staging. More LNs dissected were less likely to have missed nodal involvement. pN0 patients with a low number of LNs resected may in fact have had positive LN involvement but were misclassified. Thus, comprehensive sentinel LN dissection is recommended in EC patients. Additionally, pathologists should consider additional sections and IHC to evaluate NLNs beyond conventional histopathologic analysis.
The current study suggested that postoperative adjuvant CRT could lead to a better outcome. Wang and his colleagues demonstrated a similar result. As reported, postoperative adjuvant CRT could significantly reduce local recurrence rates and improve progression-free survival (PFS) and OS compared to surgery alone. ${ }^{23}$ Neoadjuvant CRT was not found to be a definitive protective prognostic factor in our study. Only patients who received neoadjuvant CRT and a pathological examination showing no residual carcinoma had significantly improved survival rates. In 

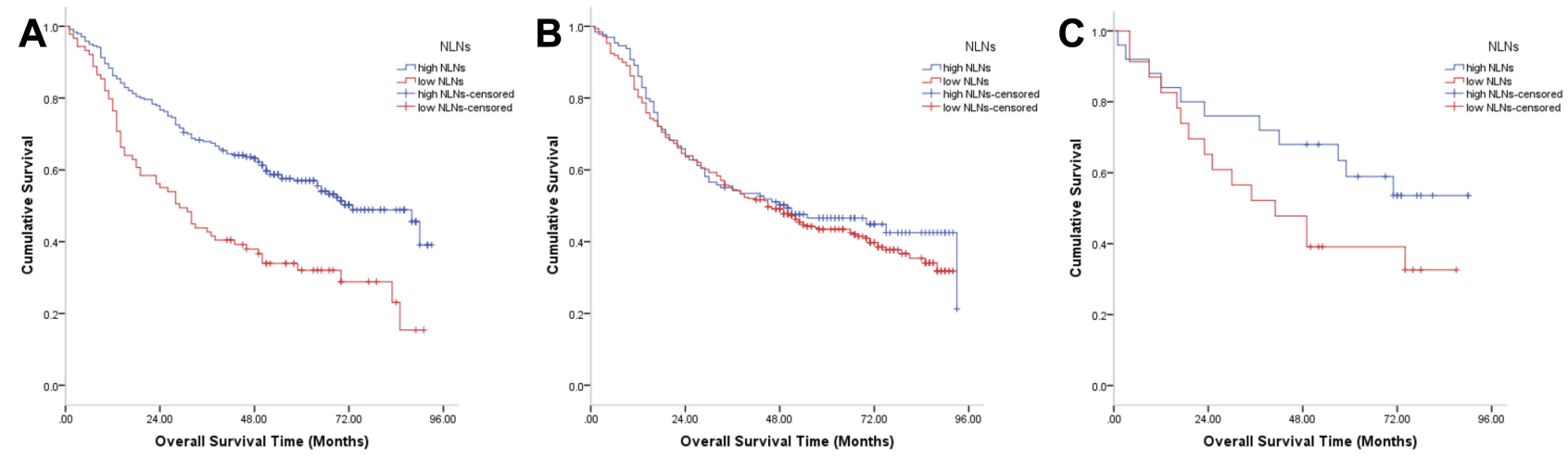

Figure 4 (A) A significant survival difference was found between high NLNs group and low NLNs for patients with three-incision. (B) No survival difference was found between high NLNs group and low NLNs group for patients with left-thoracotomy. (C) No survival difference was found between high NLNs group and low NLNs group for patients with Ivor-Lewis approach.
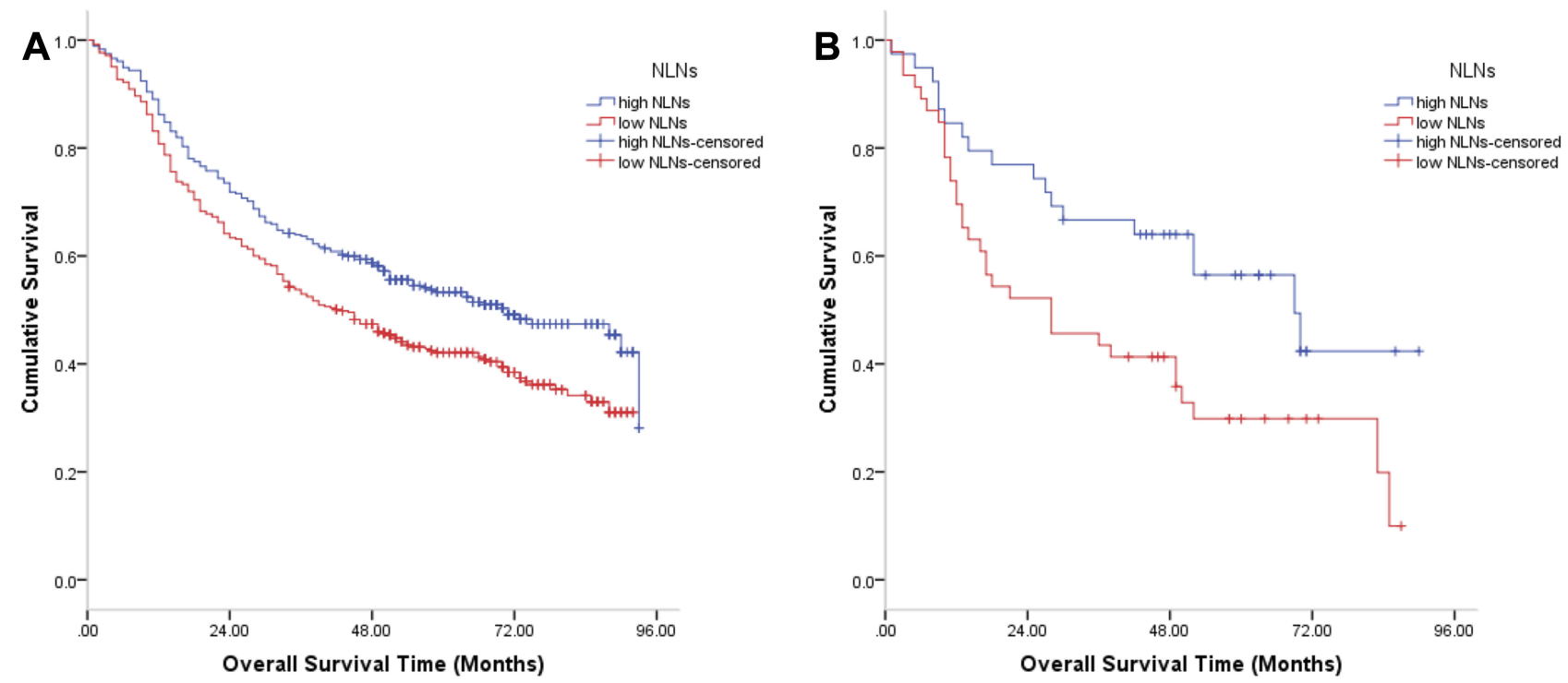

Figure 5 (A) A significant survival difference was found between high NLNs group and low NLNs group for patients without preoperative therapy. (B) A significant survival difference was found between high NLNs group and low NLNs group for patients with preoperative therapy.

addition, our study showed that the presence of LN metastases was a strong indicator of poor survival in EC, which was consistent with the results of previous studies. ${ }^{11,19,24}$ The association between depth of tumor invasion and NLN count was also investigated in the present study. The protective effect of a high number of NLNs was only observed in $\mathrm{T} 2$ and $\mathrm{T} 3$ stage cancers, but not in $\mathrm{T} 0$ and $\mathrm{T} 1$, which was consistent with the discoveries of a previous study. ${ }^{10}$ Therefore, it could be beneficial for patients to routinely receive extended lymphadenectomy when the tumor is found to infiltrate the muscularis and tunica adventitia of esophagus. In addition, our study showed that an increasing number of NLNs was associated with lower mortality, especially in cases using the three-incision approach. Because of the high risk of operation injury and postoperative complications of neck dissection, only a portion of patients in the study population who were diagnosed with cervical LN metastases in preoperative evaluation underwent threefield lymphadenectomy. There were 66 patients who received neck dissections, and no definite association found between three-field lymphadenectomy and prognosis. This finding maybe because of the small sample size. The effect of resection technique on patient outcome has been controversial. A previous study claimed that the prognostic value of NLNs count was only found in patients undergoing three-field lymphadenectomy instead of in patients receiving two-field lymphadenectomy. ${ }^{4}$ Moreover, a randomized trial found no difference in the survival rate 
between two-field and three-field lymphadenectomy. ${ }^{25}$ However, Rizk et al announced that more extensive lymphadenectomy was associated with increased survival. ${ }^{26}$ A consensus on the optimal extent of lymphadenectomy for different disease stages has not yet been concluded. In the current study, 91 patients $(28.1 \%)$ were suffered from postoperative complications after underwent 3-incisions procedure, and only 42 patients $(10.6 \%)$ had complications with the Sweet approach (Supplemental Table 1). We deduced that for patients with an early or localized lesion, extended LN dissection could clarify the stage and lead to an accurate diagnosis and more appropriate treatment. In patients with advanced disease, multidisciplinary synthetic therapies seem to be more critical than surgery alone with excessive lymphadenectomy, which may increase the incidence of complications after surgery.

The strength of this study is that we studied a large cohort of ESCC patients from two institutions. The large sample size with a considerably high follow-up rate guarantees the reliability of our results. Nevertheless, several limitations in the current study should be addressed. Firstly, this is a retrospective analysis, and more prospective researches are needed to confirm our results. Secondly, we excluded patients with tumors located in the cervical esophagus or esophagogastric junction EC. Therefore, prudence is needed when extrapolating our findings to these patients.

\section{Conclusions}

In summary, we demonstrated that a higher number of NLNs was independently associated with better OS in EC patients undergoing curative resection. The relationship between NLN count and favorable survival was more prominent in patients with $\mathrm{T} 2$ and $\mathrm{T} 3$ stage cancer. In addition, the increasing number of NLNs was associated with lower mortality, especially for patients underwent McKeown approach. Future prospective studies are needed to verify our results and to discuss the potential mechanisms underlying the prognostic value of NLNs.

\section{Disclosure}

The authors report no conflicts of interest in this work.

\section{References}

1. Bray F, Ferlay J, Soerjomataram I, et al. Global cancer statistics 2018: GLOBOCAN estimates of incidence and mortality worldwide for 36 cancers in 185 countries. CA Cancer J Clin. 2018;68(6):394-424. doi:10.3322/caac. 21492
2. Torre LA, Bray F, Siegel RL, et al. Global cancer statistics, 2012. $C A$ Cancer J Clin. 2015;65(2):87-108. doi:10.3322/caac.21262

3. Rashid F, Waraich N, Bhatti I, et al. A pre-operative elevated neutrophil: lymphocyte ratio does not predict survival from oesophageal cancer resection. World J Surg Oncol. 2010;8:1-10. doi:10.1186/ 1477-7819-8-1

4. van der Schaaf M, Johar A, Wijnhoven B, et al. Extent of lymph node removal during esophageal cancer surgery and survival. $J$ Natl Cancer Inst. 2015;107(5).

5. Rice TW, Ishwaran H, Hofstetter WL, et al; Worldwide Esophageal Cancer Collaboration, I. Recommendations for pathologic staging (pTNM) of cancer of the esophagus and esophagogastric junction for the 8th edition AJCC/UICC staging manuals. Dis Esophagus. 2016;29(8):897-905. doi:10.1111/dote.2016.29.issue-8

6. Rice TW, Blackstone EH, Rusch VW, et al. 7th edition of the AJCC cancer staging manual: esophagus and esophagogastric junction. Ann Surg Oncol. 2010;17(7):1721-1724. doi:10.1245/s10434-010-1024-1

7. Twine CP, Lewis WG, Morgan MA, et al. The assessment of prognosis of surgically resected oesophageal cancer is dependent on the number of lymph nodes examined pathologically. Histopathology. 2009;55(1):46-52. doi:10.1111/his.2009.55.issue-1

8. Tan Z, Ma G, Yang H, et al. Can lymph node ratio replace pn categories in the tumor-node-metastasis classification system for esophageal cancer? J Thorac Oncol. 2014;9(8):1214-1221. doi:10.1097/ JTO.0000000000000216

9. Zhu Z, Chen H, Yu W, et al. Number of negative lymph nodes is associated with survival in thoracic esophageal squamous cell carcinoma patients undergoing three-field lymphadenectomy. Ann Surg Oncol. 2014;21(9):2857-2863. doi:10.1245/s10434-014-3665-y

10. Hsu PK, Huang CS, Wang BY, et al. The prognostic value of the number of negative lymph nodes in esophageal cancer patients after transthoracic resection. Ann Thorac Surg. 2013;96(3):995-1001. doi:10.1016/j.athoracsur.2013.04.098

11. Wu SG, Li FY, Zhou J, et al. Prognostic value of different lymph node staging methods in esophageal squamous cell carcinoma after esophagectomy. Ann Thorac Surg. 2015;99(1):284-290. doi:10.1016/ j.athoracsur.2014.08.036

12. San-Gang W, Sun J-Y, Yang L-C, et al. Prognosis of patients with esophageal squamous cell carcinoma after esophagectomy using the $\log$ odds of positive lymph nodes. oncotarget. 2015;6(34):11.

13. Smith DD, Schwarz RR, Schwarz RE, et al. Impact of total lymph node count on staging and survival after gastrectomy for gastric cancer: data from a large US-population database. J Clin Oncol. 2005;23(28):7114-7124. doi:10.1200/JCO.2005.14.621

14. Baba Y, Watanabe M, Shigaki H, et al. Negative lymph-node count is associated with survival in patients with resected esophageal squamous cell carcinoma. Surgery. 2013;153(2):234-241. doi:10.1016/j. surg.2012.08.001

15. Li B, Xiang J, Zhang Y, et al. Comparison of Ivor-Lewis vs Sweet esophagectomy for esophageal squamous cell carcinoma: a randomized clinical trial. JAMA Surg. 2015;150(4):292-298. doi:10.1001/jamasurg.2014.2877

16. Rice TW, Shwaran H, Kelsen DP, et al. Recommendations for neoadjuvant pathologic staging (ypTNM) of cancer of the esophagus and esophagogastric junction for the 8th edition AJCC/UICC staging manuals. Dis Esophagus. 2016;29(8):7.

17. Agha RA, Borrelli MR, Vella-Baldacchino M, et al. The STROCSS statement: strengthening the reporting of cohort studies in surgery. Int J Surg. 2017;46:198-202. doi:10.1016/j.ijsu.2017.08.586

18. Hu Y, Hu C, Zhang H, et al. How does the number of resected lymph nodes influence TNM staging and prognosis for esophageal carcinoma? Ann Surg Oncol. 2010;17(3):784-790. doi:10.1245/s10434-009-0818-5

19. Bollschweiler E, Baldus SE, Schroder W, et al. Staging of esophageal carcinoma: length of tumor and number of involved regional lymph nodes. Are these independent prognostic factors? J Surg Oncol. 2006;94(5):355-363. doi:10.1002/(ISSN)1096-9098 
20. Greenstein AJ, Litle VR, Swanson SJ, et al. Effect of the number of lymph nodes sampled on postoperative survival of lymph node-negative esophageal cancer. Cancer. 2008;112(6):1239-1246. doi:10.1002/(ISSN)10970142

21. Thompson SK, Ruszkiewicz AR, Jamieson GG, et al. Isolated tumor cells in esophageal cancer: implications for the surgeon and the pathologist. Ann Surg. 2010;252(2):299-306. doi:10.1097/SLA.0b013e3181e61e15

22. Koenig AM, Prenzel KL, Bogoevski D, et al. Strong impact of micrometastatic tumor cell load in patients with esophageal carcinoma. Ann Surg Oncol. 2009;16(2):454-462. doi:10.1245/ s10434-008-0169-7

23. Wang ZW, Luan ZP, Zhang W, et al. Postoperative chemoradiotherapy improves survival in esophageal squamous cell cancer with extracapsular lymph node extension. Neoplasma. 2014;61(6):732-738. doi:10.4149/ neo_2014_089
24. Baba M, Aikou T, Natsugoe S, et al. Lymph node and perinodal tissue tumor involvement in patients with esophagectomy and three-field lymphadenectomy for carcinoma of the esophagus. J Surg Oncol. 1997;64:5. doi:10.1002/(ISSN)1096-9098

25. Nishihira T, Hirayama K, Mori S, et al. A prospective randomized trial of extended cervical and superior mediastinal lymphadenectomy for carcinoma of the thoracic esophagus. Am J Surg. 1998;175:5. doi:10.1016/S0002-9610(97)00227-4

26. Rizk NP, Ishwaran H, Rice TW, et al. Optimum lymphadenectomy for esophageal cancer. Ann Surg. 2010;251(1):46-50. doi:10.1097/ SLA.0b013e3181b2f6ee

\section{Publish your work in this journal}

Cancer Management and Research is an international, peer-reviewed open access journal focusing on cancer research and the optimal use of preventative and integrated treatment interventions to achieve improved outcomes, enhanced survival and quality of life for the cancer patient.
The manuscript management system is completely online and includes a very quick and fair peer-review system, which is all easy to use. Visit http://www.dovepress.com/testimonials.php to read real quotes from published authors. 